\title{
OS SEMIMETAIS NA ORIGEM E EVOLUÇÃO DA VIDA
}

\author{
Manuel Aureliano e Pedro A. Nolasco \\ Departamento de Ciências Biológicas e Bioengenharia, Faculdade de Ciências e Tecnologia, Universidade do Algarve, 8005-139 \\ Faro, Portugal \\ João J. R. Fraústo da Silva e José Armando L. da Silva* \\ Centro de Química Estrutural, Complexo I, Instituto Superior Técnico, Universidade Técnica de Lisboa, Av. Rovisco Pais, 1, \\ 1049-001 Lisboa, Portugal
}

Recebido em 16/9/11; aceito em 2/12/11; publicado na web em 23/1/12

\begin{abstract}
METALLOIDS IN ORIGIN AND EVOLUTION OF LIFE. Metalloids have characteristics between metals and non-metals which give them, in some cases, specific properties. At least two of this chemical elements, boron and silicon, are essential to a significant number of living organisms and since some years ago it has been observed that the same metalloids may be involved in the synthesis and stabilization of some molecules relevant to the origin of life.
\end{abstract}

Keywords: RNA world; boron; silicon.

\section{INTRODUÇÃO}

Embora se verifique uma tendência para abandonar o conceito de semimetal (metaloide), tanto a União Internacional da Química Pura e Aplicada como a Sociedade Brasileira de Química não os incluem separadamente nas suas tabelas periódicas dos elementos, ${ }^{1}$ continuam a publicar-se muitos trabalhos sobre semimetais, dado que têm algumas especificidades com aplicações, por exemplo, no fabrico de semicondutores. ${ }^{2}$ No grupo dos semimetais (Figura 1) são, geralmente, incluídos os seguintes elementos químicos: boro (grupo 13), silício e germânio (grupo 14), arsénio e antimónio (grupo 15), e telúrio (grupo 16), sendo, por vezes, a designação alargada ao polónio (grupo 16) e ao ástato (grupo 17). Caracterizam-se por terem propriedades físicas e/ou químicas de metais e de não metais. ${ }^{3}$ Note-se que o ástato apresenta propriedades dos semimetais, embora pertença ao grupo dos halogéneos.

Este artigo teve por objetivo descrever os semimetais com características mais próximas dos não metais e com pelo menos um isótopo estável, que possam ter dado contributos no processo de origem e
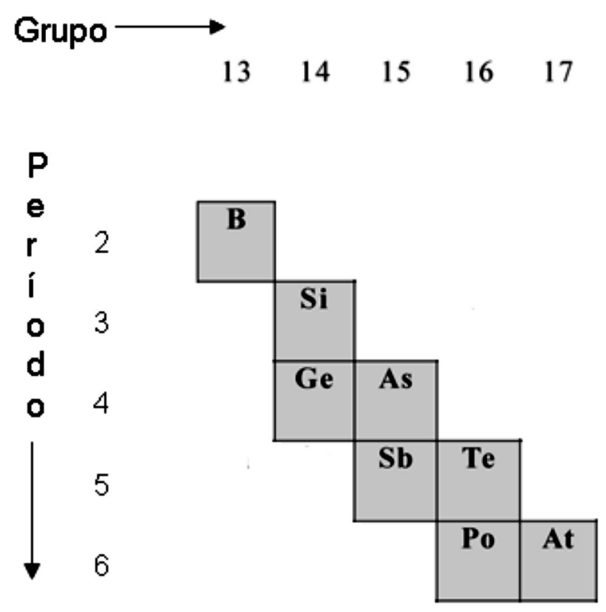

Figura 1. Localização dos semimetais na Tabela Periódica dos Elementos

*e-mail: pcd1950@ist.utl.pt evolução da vida na Terra. De notar também que atualmente os elementos boro, silício, arsénio e telúrio têm sido identificados como tendo funções ou eventuais desempenhos casuísticos nos seres vivos. Por outro lado, todos os isótopos de polónio e de ástato são radioativos, e por isso não são adequados aos processos metabólicos que ocorrem nos sistemas biológicos, pois originam reações que degradam as biomoléculas, como consequência do seu decaimento radioativo. ${ }^{3-6}$

\section{OS SEMIMETAIS E OS SISTEMAS BIOLÓGICOS}

Antes de se analisar os semimetais na sua associação com estruturas biológicas (ou eventualmente pré-biológicas) é conveniente efetuar algumas considerações acerca das razões gerais para a escolha dos elementos químicos pelos organismos vivos, as quais podem ser generalizadas para as estruturas pré-biológicas. Essas razões são, pelo menos, duas das seguintes: abundância, disponibilidade (que, de maneira simples, está relacionada com possibilidade dos elementos químicos serem solubilizados sem dispêndio elevado de energia) e eficiência funcional [a aptidão para possibilitarem determinadas reações (bio)químicas]. ${ }^{4,7}$

Muitos elementos químicos são incorporados nos seres vivos na forma de compostos químicos com alguma complexidade. Todavia, no período de transição entre os sistemas minerológicos e a ocorrência dos primeiros organismos vivos, a escolha dos elementos químicos teve em conta as limitações da quantidade, o modo como ocorriam os materiais acessíveis (maioritariamente de composição mais simples do que os atuais) e ainda das reações em que poderiam participar. ${ }^{4,7}$ No respeitante ao período pré-biótico, os reservatórios de água líquida, eventualmente em ambientes sujeitos a pressões elevadas, podem ter sido locais onde tenham ocorrido reações pré-bióticas e as razões acima mencionadas podem ter sido condicionadas por esses meios não serem homogéneos, o que afetou a abundância e a disponibilidade dos elementos químicos com a localização. Deste modo, é possível que alguns elementos mais abundantes na globalidade tenham dado um contributo menos significativo na formação de estruturas pré-bióticas em regiões que reuniam condições para a ocorrência de reações pré-biológicas. Além disso, a disponibilidade dos vários elementos químicos foi-se alterando ao longo do tempo em diversos locais, ${ }^{4,8-10}$ o que em períodos críticos pode ter imposto limitações ao tipo de estruturas que aí se formariam. 
Nos cerca de 4,5 mil milhões de anos do planeta Terra ocorreram modificações ambientais que conduziram à alteração da disponibilidade de alguns elementos químicos. De facto, algumas espécies químicas que inicialmente não se encontravam disponíveis, tornaram-se progressivamente mais disponíveis com mudanças ambientais, enquanto outras se tornaram menos disponíveis. Como a atmosfera terrestre foi nos primórdios da Vida mais redutora, a ocorrência de sulfuretos era favorecida e como muitos destes compostos continham metais de transição pouco solúveis estes estavam muito pouco disponíveis. Com a oxigenação da atmosfera os sulfuretos foram sendo progressivamente oxidados a sulfatos mais solúveis e, por exemplo, adicionalmente, o molibdénio passou a ocorrer como molibdato, ficando este metal mais disponível. Todavia, o ferro passou a predominar no seu estado de oxidação três, o que fez diminuir a sua disponibilidade. Como é de esperar, estas modificações provocaram uma evolução ao nível dos organismos, apesar dos processos químicos nas células não terem tido alterações bruscas. ${ }^{4,8,11}$

Uma célula, em geral, contém cerca de 20 elementos químicos diferentes (não chegando a 30 o número de elementos essenciais em todos os tipos de organismos vivos) e o seu funcionamento depende da forma como esses elementos estão distribuídos. Na sua distribuição pelos grupos da Tabela Periódica dos Elementos é pequeno o número de grupos com mais do que dois elementos participantes nos processos metabólicos que ocorrem nas células. Todavia, o desempenho adequado dos organismos vivos depende da forma como os elementos químicos essenciais ocorrem nestes (por exemplo, ao nível do seu estado de oxidação) ou ainda como a sua quantidade condiciona as atividades metabólicas. Por isso, podem tornar-se tóxicos, tal como os não essenciais, por favorecem reações inconvenientes. ${ }^{4}$ Deste modo, estas palavras escritas na primeira metade do século XVI por Theophrastus Philippus Aureolus Bombastus von Hohenheim (1493-1541), mais conhecido como Paracelsus, considerado o fundador da Toxicologia, ainda mantêm atualidade: «Alle Ding' sind Gift, und nichts ohn' Gift; allein die Dosis macht, daß ein Ding kein Gift ist», ou na versão condensada em latim «Sola dosis facit venenum», podendo a primeira ser traduzida por «Todas as substâncias são venenos; nenhuma não o é. A dose certa diferencia o veneno do remédio», adaptado da ref. 5.

É de salientar que para qualquer organismo vivo assegurar a sua sobrevivência num ambiente, que entretanto tenha sofrido alterações pela variação da disponibilidade de algum(ns) elemento(s) químico(s), tem de adaptar-se à situação ou, em alternativa, mudar de habitat. Caso permaneça pode ter de lidar com um (ou mais) elemento(s) químico(s) tóxico(s) não essencial(ais) que inicialmente tem tendência a rejeitar. Esta resposta serve eventualmente como sinalizador de risco, podendo acontecer numa fase seguinte que esse(s) elemento(s) químico(s) ocorra(m) numa forma mais inócua, caso $\mathrm{seja}(\mathrm{m})$ incorporado(s) no metabolismo atuando como sinalizador(es) interno(s) ou vir(em) mesmo a ser utilizado(s) em funções específicas. Deste modo, alguns elementos químicos que fiquem mais disponíveis podem vir a tornar-se essenciais por serem eficientes para uma dada função. Esta alteração pode favorecer os mecanismos evolutivos. ${ }^{4}$

Como acerca do processo de origem da vida os conhecimentos são muito limitados, antes de se abordar esse tema e o eventual desempenho dos semimetais nesse processo, analisar-se-ão as abundâncias na Terra e as atividades metabólicas do boro, silício, arsénio e telúrio.

\section{Abundância e atividades metabólicas dos semimetais boro, silício, arsénio e telúrio}

Os semimetais, boro, silício, arsénio e telúrio, apresentam funções ou podem estar associados a processos bioquímicos que ocorrem nos seres vivos. Apenas o boro e o sílicio ocorrem em um único estado de oxidação e sempre com mais do que uma ligação do semimetal a um átomo de oxigénio. $\mathrm{O}$ boro é o $11^{\circ}$ elemento químico mais abundante na água do mar, mas ocupa a $38^{\mathrm{a}}$ posição em termos de abundância na crusta terrestre, ocorrendo nesta, quando na forma de borato, em quantidades significativas próximo de regiões com atividade vulcânica intensa. ${ }^{12} \mathrm{O}$ silício é o $2^{\circ}$ elemento químico mais abundante na crusta terrestre. $\mathrm{O}$ arsénio e o telúrio são, respetivamente, o $53^{\circ}$ e o $72^{\circ}$ elementos mais abundantes na crusta terrestre e também muito pouco abundantes na água do mar., ${ }^{4,13}$

\section{Participação do boro na biologia}

Ao valor de $\mathrm{pH}$ fisiológico, o boro, como ácido bórico $\left(\mathrm{HBO}_{3}\right)$, é uma espécie neutra, devido ao valor baixo da sua constante de dissociação, $\mathrm{pK}_{\mathrm{a}}=9,2$, o que lhe permite atravessar facilmente as membranas celulares. No ambiente celular participa em reações de condensação com cis-dióis, ocorrendo ligado quimicamente com quatro átomos de oxigénio.

Desde 1923 é reconhecido que o boro é um elemento químico essencial nas plantas superiores (em que participa na expansão da parede celular, facilitando a divisão celular e ocorrendo associado a polissacáridos), tendo sido, mais tarde, demonstrada a sua essencialidade em bactérias. Em algumas bactérias são produzidos antibióticos naturais contendo boro e este elemento químico pode também participar na comunicação entre membros deste tipo de micro-organismos, através da libertação para o meio extracelular de moléculas sinalizadoras denominadas autoindutores, processo designado por quorum-sensing e que permite a formação de biofilmes. ${ }^{14}$ Por exemplo, o autoindutor AI-2 é produzido por várias dezenas de espécies bacterianas, podendo permitir a comunicação entre espécies. No caso das bactérias Vibrio, estas apresentam essa estrutura contendo um átomo de boro ligado como diéster, enquanto que na Escherichia coli não apresenta este elemento químico. Note-se que, o habitat da V. harvey é o mar, onde a concentração de boro é significativa, o que não acontece no meio onde vive a $E$. coli. ${ }^{4,15}$ É também conhecida a presença de boro em um fóssil de Solenopora jurassica, uma espécie extinta de alga vermelha. ${ }^{16}$ Curiosamente, em todos os casos, incluindo no fóssil, a sua forma de coordenação é equivalente (Figura 2), sendo efetuada através de átomos de oxigénio.

O boro é muito menos importante em biologia do que o carbono e o silício, mas o facto de ser mais pequeno do que os outros dois elementos químicos pode favorecer a sua participação na estabilização de estruturas de várias biomoléculas. ${ }^{4}$

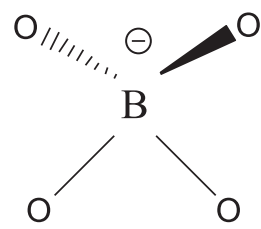

Figura 2. Representação geral da forma de coordenação de boro em moléculas biológicas

\section{Participação do silício na biologia}

O sílício é do mesmo grupo químico do carbono, mas é cerca de seiscentas vezes mais abundante do que este elemento químico na crusta terrestre. Todavia, os organismos vivos usam o carbono na estrutura básica das suas biomoléculas, devido às suas propriedades químicas. A menor estabilidade da ligação química $\mathrm{Si}$-Si, quando comparada com a correspondente ligação C-C, mostra como seria reduzida a estabilidade das macrobiomoléculas se fossem constituídas por silício. Por outro lado, as energias de ligação de carbono com os outros elementos químicos básicos presentes nos seres vivos (hidrogénio, oxigénio e nitrogénio) permitem verificar a maior 
versatilidade do carbono em comparação com o silício nos sistemas biológicos. O semimetal silício forma com o oxigénio, na Natureza, compostos do tipo-Si-O-Si-, os quais têm tendência a gerar estruturas tridimensionais e serem dificilmente funcionalizáveis para ocorrerem nos seres vivos.

Nos organismos vivos, o silício ocorre normalmente em estruturas amorfas com a composição $\mathrm{SiO}_{\mathrm{n}}(\mathrm{OH})_{4-2 \mathrm{n}}$. Apesar das suas limitações acima referidas, este semimetal é fundamental em muitos eucariotas unicelulares e em algumas esponjas (ocorrendo em ambos os casos em biominerais), em plantas nesta última forma e também como oligoelemento, ou elemento vestigial, e neste caso também nos animais superiores. Nas plantas, o silício favorece o crescimento, aumenta a resistência a fungos e reforça a resistência mecânica, enquanto que nos animais se encontra associado ao processo de nucleação do fosfato de cálcio, necessário na formação dos tecidos ósseos e na manutenção da integridade dos tecidos, designadamente pela estabilização de glicoproteínas associadas ao colagénio. Na maioria dos casos, o silício ocorre em biominerais de sílica, embora em alguns possa estar associado a macrobiomoléculas. ${ }^{4,17}$

\section{Participação do arsénio na biologia}

$\mathrm{O}$ arsénio ocorre disperso no meio ambiente e a atividade humana tem-o tornado cada vez mais disponível aos sistemas biológicos. Os micro-organismos podem, por exemplo, através das suas reações, transferí-lo para os aquíferos, o que tem causado problemas na saúde pública, provocando, nomeadamente, «arsenicose» numa larga escala, em países como Bangladesh e Índia. Na sua forma oxidada, o arsenato compete com o fosfato e inibe o processo de fosforilação oxidativa que ocorre nos mitocôndrios, afetando a bioenergética das células porque bloqueia a produção de ATP, a moeda de troca energética nos seres vivos. Por outro lado, na sua forma reduzida catiónica coordena-se com grupos tiólicos, causando perturbações metabólicas. ${ }^{4,18}$

Com o aumento da disponibilidade do arsénio, alguns seres vivos têm desenvolvido mecanismos de desintoxicação e de utilização deste semimetal, como acontece com alguns organismos marinhos, por exemplo, peixes e focas, que o incluem em compostos orgânicos menos tóxicos. Atualmente, conhecem-se mais de duas dezenas de compostos químicos de arsénio presentes em organismos vivos, incluindo açúcares e tióis. O fungo Saccharomyces cerevisiae contém uma enzima que reduz arsénio, a redutase de arsenato, a qual tem homologias com algumas enzimas que quebram ligações de grupos fosfato, as fosfatases, o que sugere ter a redutase resultado destas últimas. Diversos micro-organismos, numa gama vasta de habitats, utilizam oxoaniões com arsénio para gerar energia, tanto como arsenito $\left(\mathrm{AsO}_{3}{ }^{-}\right)$como através do arsenato $\left(\mathrm{AsO}_{4}{ }^{3-}\right)$. É de referir também, que alguns fetos do género Pteris são hiperacumuladores de arsénio, tendo sido verificado que um maior teor no solo deste elemento químico estimula o crescimento das espécies, sendo nestes fetos transportado como arsenato pelos transportadores de fosfato e posteriormente reduzido. Por outro lado, a nível celular foram descritas «bombas iónicas» (P-ATPases ou E1E2-ATPases) que transportam arsénio através das membranas. Estudos de especiação efetuados na $P$. vittata, mostraram que o arsénio ocorre maioritariamente como $\mathrm{As}^{3+}$ que é, curiosamente, considerada a forma mais tóxica para os seres vivos. Por outro lado, a bactéria extremófila GFAJ-1 parece poder utilizar arsénio no seu metabolismo, embora este efeito seja assunto polémico. ${ }^{4,18-20}$

Será que o arsénio é um elemento químico que progressivamente está a ser incorporado por alguns seres vivos?

\section{Participação do telúrio na biologia}

São conhecidos casos de fungos em meios sem fontes de enxofre, mas na presença de sais de telúrio que sintetizam aminoácidos com este semimetal em vez de enxofre. ${ }^{21}$ Note-se que o enxofre, na cisteína, é substituído formalmente pelo selénio, na selenocisteína, a qual é atualmente conhecida como o $21^{\circ}$ aminoácido. ${ }^{22}$

Por outro lado, foram identificadas bactérias anaeróbias com habitats em ventarolas marinhas no oceano profundo que podem usar telurato e telurito como aceitadores de eletrões na cadeia respiratória. ${ }^{21}$

\section{Ocorrência de semimetais nos organismos vivos}

A ocorrência de semimetais nos atuais organismos vivos pode resultar do processo evolutivo, mas não é de excluir o seu contributo inicial na formação das estruturas pré-biológicas. Ao boro e ao silício, devido às suas abundâncias e importância nos seres vivos atuais, podem ser atribuídos contributos importantes nesse processo. No caso particular do boro é de referir a sua relativa abundância nos oceanos atuais. ${ }^{4,13}$ Considerando que o meio aquoso pode ter sido relevante em algumas reações pré-bióticas e como o boro tem a tendência para acumular-se na crusta terrestre em zonas com intensa atividade vulcânica, ${ }^{12}$ não é de excluir que este semimetal tenha sido significativamente abundante em regiões do mesmo tipo nos fundos marinhos, locais admissíveis para terem ocorrido reações associadas com a origem da vida na Terra.

O arsénio é um elemento químico do mesmo grupo do fósforo, sendo estes, respetivamente, os elementos químicos centrais do arsenato e do fosfato, espécies químicas com características químicas semelhantes, o que poderia favorecer a ocorrência do arsenato, em vez do fosfato, nas múltiplas funções biológicas em que o fosfato se encontra envolvido. No entanto, o arsenato reduz-se no meio biológico ao estado trivalente, o que não acontece com o fosfato. Além disso, os ésteres de arsenato hidrolisam mais rapidamente do que os ésteres de fosfato, pelo que não são boas fontes para armazenamento de energia nos organismos vivos. ${ }^{4}$ Note-se, no entanto, que a polémica acerca do arsénio na biologia é atualmente muito significativa. ${ }^{20}$ Estas características do arsénio e, ainda, a menor abundância de arsénio do que de fósforo, podem ter condicionado a sua ocorrência em estruturas pré-biológicas.

Relativamente ao telúrio, é de notar que o selénio, ambos do mesmo grupo (16), mas este do quarto período da Tabela Periódica do Elementos, deve ter sido incorporado tardiamente no metabolismo, ${ }^{4}$ talvez por ser pouco abundante. ${ }^{13}$ De facto, o telúrio é ainda menos abundante do que o selénio. ${ }^{13}$ Como nesse grupo são essenciais para todos os seres vivos três elementos (oxigénio, enxofre e selénio), ${ }^{4}$ é pouco provável a ocorrência de telúrio em estruturas pré-biológicas. Os casos referidos de telúrio nos organismos vivos atuais ${ }^{21}$ podem resultar de pressões ambientais que algumas analogias químicas favorecem.

De seguida, serão efetuados alguns comentários acerca da origem da vida e a possível participação dos semimetais neste processo.

\section{A ORIGEM DA VIDA E O RNA WORLD}

As primeiras interpretações científicas acerca da origem da vida admitiam que no ambiente terrestre primitivo encontrar-se-iam disponíveis os componentes necessários para a génese da vida. ${ }^{23,24}$ A mais conhecida experiência inicial que tem dado suporte a estas hipóteses descreveu a síntese de algumas moléculas biológicas mais simples. ${ }^{25}$ Todavia, dada a interdependência dos sistemas genético e metabólico nos organismos vivos atuais, as formulações propostas não resolvem a divergência relativamente ao qual surgiu primeiro, aspeto conhecido como o paradoxo da galinha e do ovo. ${ }^{26-29}$ A hipótese $R N A$ world $^{30}$ pode permitir superar este paradoxo por considerar que os sistemas genético e metabólico tiveram uma origem conjunta e a génese de ambos ocorreu com o aparecimento de moléculas de RNA 
(ácido ribonucleico ou RiboNucleic Acid), o qual é constituído por ribonucleótidos. Os ribonucleótidos contêm fosfato, ribose e uma nucleobase (adenina, guanina, citosina ou uracilo). Adicionalmente, apresentam a capacidade de serem catalisadores biológicos, constituídos por RNA (denominadas ribozimas), promovendo a sua autorreplicação. Assim, permitiu-se que a informação não fosse perdida no fim de cada geração molecular (função genética). ${ }^{28-32}$

O suporte da hipótese do RNA world requer a formação de ribozimas com capacidade de catalisar uma significativa gama de reações. ${ }^{27-29}$ Saliente-se que algumas coenzimas, como a dinucleótido de flavina e adenina, contêm adenina, ribose e fosfato, tal como o RNA. As coenzimas podem estar envolvidas em reações de transferência de grupos químicos (transferases) e também em reações de oxidação-redução (óxido-redutases), podendo, tal como as ribozimas, ser «descendentes diretos» dos processos catalíticos pré-biológicos. ${ }^{33}$

A hipótese do RNA world reúne uma parte muito significativa da investigação feita na área da química pré-biótica. Contudo, determinados passos na formação do RNA ainda se encontram por esclarecer. ${ }^{27} \mathrm{~A}$ existência de um ambiente redutor nos primórdios da vida da Terra é fundamental, pois se assim não fosse a síntese de moléculas orgânicas pré-bióticas seria muito improvável. ${ }^{27}$ Os ambientes das ventarolas nos oceanos têm sido sugeridos como sendo locais privilegiados da formação de moléculas relevantes para a origem e evolução da vida na Terra. ${ }^{34}$

Outros autores consideram que o RNA (ou um seu precursor) pode não ter tido origem prebiótica. Este confronto de pontos de vista foi recentemente analisado. ${ }^{35}$

\section{Vias de síntese pré-biótica de RNA}

O surgimento das primeiras moléculas de RNA pode ter acontecido pela síntese a partir dos seus precursores, por meio de um processo não catalisado enzimaticamente ${ }^{26}$ ou através de uma transição a partir de uma molécula funcional antecessora de RNA. ${ }^{29}$ Até ao presente, não foi encontrado nenhum ser vivo com vestígios deste último tipo de estruturas e, nos casos propostos, estes não são tão eficientes como o RNA. Além disso, não foi delineado nenhum percurso de transição para as estruturas atuais. ${ }^{34}$

A síntese laboratorial de RNA, simulando vias plausíveis do ponto de vista pré-biótico, não foi ainda alcançada, embora a síntese de ribose e de nucleobases tenha sido efetuada, ${ }^{27}$ mas a dos ribonucleótidos é ainda repleta de dificuldades. Para além da síntese, constituem fatores difíceis de ultrapassar a baixa estabilidade da ribose e das nucleobases, a reduzida disponibilidade de fosfato ${ }^{36}$ e a conjugação adequada destes componentes na síntese dos ribonucleótidos. ${ }^{27,37,38}$ Também a síntese direta de ribonucleósidos de pirimidinas com uracilo ou citosina ainda não foi conseguida, embora uma versão ativada tenha sido obtida. ${ }^{39}$ Recentemente, estruturas relacionáveis com os ribonucleótidos (de adenina ou de guanina) foram conseguidas num só passo na presença da nucleobase respetiva, da ribose e de uma fonte de fósforo. ${ }^{40}$ Por outro lado, a polimerização de nucleótidos na presença de compostos inorgânicos tem tido desenvolvimentos interessantes. Estes estudos têm sido criticados por várias razões, incluindo a sua baixa probabilidade de terem ocorrido em ambientes pré-bióticos. ${ }^{41}$

\section{Semimetais na origem da vida}

\section{Sintese de ribose}

A ribose ocorre em todo o tipo de organismos vivos e seus derivados estão presentes em várias biomoléculas fundamentais no metabolismo, o que sugere que possa ter estado envolvida na química pré-biológica. A reação da formose, descoberta em 1861, é reconhecida como uma via de síntese pré-biótica da ribose, uma vez que é autocatalítica e torna possível obter uma mistura complexa de monossacáridos a partir de um composto simples, o formaldeído. Este mecanismo ocorre em água, na presença de hidróxido de cálcio e requer um aquecimento moderado. Mais especificamente, a síntese de ribose ocorre numa reação secundária do ciclo, através de uma condensação aldólica entre uma molécula de glicolaldeído e uma de gliceraldeído. ${ }^{27,42}$ Apesar do ciclo da formose ser plausível em condições pré-bióticas, ${ }^{43}$ é pouco eficiente, pois a velocidade de reação é baixa e a quantidade da ribose produzida é muito pequena relativamente à quantidade total de produtos. ${ }^{42}$ Além disto, a reduzida estabilidade em solução da ribose dificulta a sua acumulação no meio reacional. ${ }^{34}$ Este aspeto, torna necessária a sua acumulação ao longo do tempo e isso implica a sua estabilização. A presença de iões metálicos pode contribuir para a estabilização da ribose, pois foi previamente descrito que formam complexos com determinadas conformações dos monossacáridos, nomeadamente da ribose, através da coordenação com os grupos de tipo hidroxilo dos carbonos C1, C2 e C3, tal como se verificou com oxoiões de molibdénio, tungsténio e urânio. ${ }^{44}$ Também o vanadato ${ }^{45} \mathrm{e} o$ arsenato ${ }^{46}$ complexam a ribose e o molibdato ${ }^{47}$ favorece a síntese desta pentose. A complexação destes oxoiões com os açúcares permitiriam que estes tivessem conformações favoráveis a determinadas reações que não seriam possíveis na ausência destas espécies químicas, embora não seja plausível a ocorrência significativa destes oxoiões no ambiente redutor pré-biótico. ${ }^{4}$ Estratégias de síntese envolvendo outros iões inorgânicos têm sido desenvolvidas, como a catálise do processo por iões $\mathrm{Pb}^{2+},{ }^{42}$ mas a não ocorrência deste metal no metabolismo dos seres vivos ${ }^{4,8}$ pode indicar a sua não participação nesta reação nos processos da origem da vida na Terra primitiva.

Foi verificado que a formação de compostos entre o borato e intermediários do ciclo da formose promove a síntese de pentoses através da ligação do borato ao gliceraldeído (nos grupos hidroxilos dos carbonos C2 e C3), inibindo a sua capacidade de atuar como nucleófilo, permitindo-lhe que possa reagir posteriormente com o glicoaldeído originando várias pentoses, entre as quais a ribose. ${ }^{48}$ Uma vez que se observou que os compostos de borato-ribose são mais estáveis termodinamicamente, ${ }^{49}$ foi sugerido que a síntese da ribose fosse promovida através do direcionamento do ciclo da formose, que devido à sua seleção especifica relativamente às outras pentoses produzidas permite diminuir a variedade de produtos obtidos.

Através deste processo de síntese é possível formar estruturas contendo até dois monossacáridos, ligadas ao borato através de dois carbonos adjacentes, dependendo o local de ligação do tipo de açúcar. ${ }^{48,50}$ No caso da $\alpha$-D-ribose, isómero mais adequado à síntese dos ribonucleótidos, a ligação química do borato com a pentose é feita com os grupos hidroxilo dos carbonos C1 e C2 ou C2 e C3, tendo a segunda conformação a particularidade de as posições $\mathrm{C} 1$ e C5 ficarem livres, possibilitando a posterior adição dos restantes constituintes dos ribonucleótidos. ${ }^{48,50}$ Assim, além do papel de catalisador da síntese de ribose, o borato pode desempenhar um papel de estabilizador deste açúcar porque, como a reatividade das estruturas borato-ribose é bastante inferior à dos monossacáridos livres, a formação destes compostos possibilitaria contornar o problema da estabilidade da ribose, permitindo assim a acumulação deste açúcar em meio pré-biótico. ${ }^{48,50}$ Verificou-se que o borato forma compostos com a ribose com estequiometria 1:1 ou 1:2 (Figura 3).

Como no meio ambiente se verifica muitas vezes a coexistência de diversos iões, um facto interessante a analisar é a influência de outros aniões abundantes nos oceanos, tais como carbonato e sulfato, sobre o efeito estabilizador do borato. Verificou-se que em atmosfera de nitrogénio molecular, a pH básico e à temperatura ambiente, o sulfato não exerce qualquer influência sobre a estabilidade 

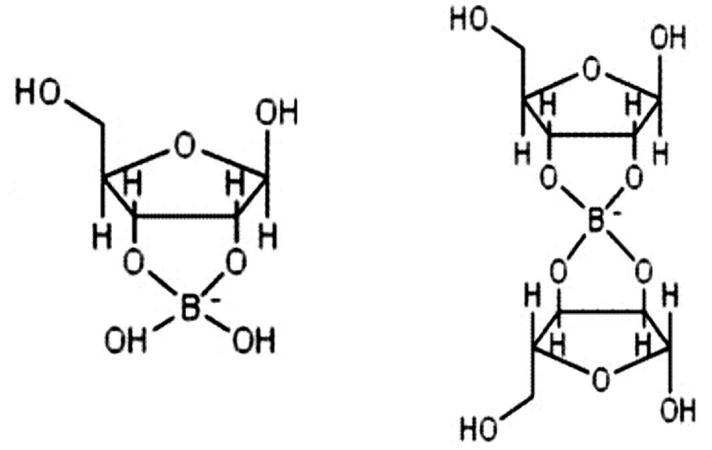

Figura 3. Formação de complexos de boro com o anómero $\beta$ da ribose, com estequiometria 1:1 (lado esquerdo) ou 1:2 (lado direito). Adaptada da ref. 50

da ribose nem dos compostos de borato-ribose e o carbonato não degrada de forma significativa a ribose, caso esta esteja associada ao borato. ${ }^{50}$ Além disso, o borato favorece as formas furanósicas da ribose,${ }^{50}$ modo como ocorre nos organismos vivos. De facto, as formas piranósicas da ribose são muito mais abundantes em solução aquosa do que as formas furanósicas, que se encontram neste meio em percentagens reduzidas. Esta característica de o boro favorecer as formas furanósicas da ribose é única quando comparada com a de outros aniões mais abundantes presentes na principal fonte de água líquida na Terra, os oceanos..$^{50,51}$

Com uma abundância na crusta terrestre mais elevada do que a do boro, o silício, ${ }^{13}$ como silicato, forma compostos com intermediários do ciclo da formose, promovendo a síntese de monossacáridos de maior dimensão, entre os quais as pentoses (ribose). Apesar deste sistema de catálise não ser específico para a síntese de ribose, é esperado que a produção desta seja promovida relativamente a outras pentoses pois as estruturas silicato-ribose são mais estáveis termodinamicamente. Além da função de catalisador, o silicato pode também estabilizar os monossacáridos produzidos durante o ciclo da formose. Todavia, este desempenho pode ser muito limitado dado que os silicatos são solúveis em meio muito básico e os compostos de silicato-monossacáridos degradam-se neste meio em pouco tempo. ${ }^{52-55}$

\section{Sintese de nucleobases}

Várias hipóteses descrevem as vias de síntese das nucleobases usando como matéria-prima compostos mais simples como o cianoacetileno, no caso de síntese de pirimidinas, ou mesmo a formamida, tanto na síntese de purinas como de pirimidinas. Contudo, as vias de síntese descritas necessitam de uma concentração inicial dos reagentes elevada, o que não deve ter ocorrido em ambiente pré-biótico. ${ }^{27}$

Foram sugeridos métodos com a participação catalítica de vários minerais, tais como a pirite $\left(\mathrm{FeS}_{2}\right)$, a covelite $(\mathrm{CuS})$ e a calcopirite $\left(\mathrm{FeCuS}_{2}\right),{ }^{56,57}$ muito difundidos na crusta terrestre, assim como com compostos de zircónio. ${ }^{58}$ Mais recentemente, foi efetuada a síntese de nucleobases, derivados de aminoácidos e ácidos carboxílicos na presença de minerais de borato. ${ }^{59}$ Estas reações envolvendo compostos inorgânicos ${ }^{56,58,59}$ ocorrem em formamida a $160{ }^{\circ} \mathrm{C}$ e o boro tem um comportamento similar aos outros elementos químicos.

Além destes, já foram também propostos sistemas sem a intervenção iões inorgânicos, em que a concentração dos reagentes iniciais foi amplificada através do sequestro de moléculas de água em solução, por exemplo, através de ciclos de evaporação ou parcial congelamento do meio reacional..$^{60-65}$

\section{Polimerização de ribonucleótidos}

$\mathrm{O}$ uso de argilas como sistema de armazenamento e replicação de informação foi descrito há mais de 50 anos. ${ }^{66}$ Adicionalmente, foi sugerido que as argilas poderiam ter permitido a polimerização dos nucleótidos. A polimerização de ribonucleótidos só se torna funcional se o oligo-ribonucleótido sintetizado possuir um tamanho entre 50 a 100 mer. ${ }^{67-69}$ A replicação destas moléculas requer apenas o emparelhamento do ribonucleótido a ser inserido com a cadeia a ser copiada, o «molde». Esta interação permite que o ribonucleótido seja orientado e posicionado favoravelmente à formação de uma ligação fosfodiéster. Na ausência de um molde, a polimerização torna-se mais difícil, já que os ribonucleótidos não se polimerizam espontaneamente em solução. ${ }^{69} \mathrm{~A}$ formação de oligo-ribonucleótidos com tamanho não superior a 25 mer ocorre com uma elevada energia de ativação, sendo esta reduzida através de catálise química. Pensa-se que a função do catalisador seja a de orientar os ribonucleótidos, de maneira a facilitar a formação de ligações intermoleculares, além de ativar o grupo hidroxilo, onde irá ser estabelecida a ligação fosfodiéster $3{ }^{\prime}-5{ }^{\prime} \cdot{ }^{70}$ Nestes exemplos descritos são utilizados como substrato ribonucleótidos ativados, em vez de ribonucleótidos, como forma de se aumentar a eficácia, já que a polimerização destes é muito lenta. ${ }^{70-72} \mathrm{O}$ mecanismo de catálise da polimerização de ribonucleótidos por argilas montemorilonite $^{73}$ está intimamente ligada à sua estrutura, pois pensa-se que este ocorra através da adsorção de ribonucleótidos às camadas da argila. ${ }^{74,75}$ Deste modo, para se perceber melhor a função que os iões inorgânicos desempenham neste sistema de catálise, é necessário conhecer estruturalmente o catalisador e a forma como decorre a adsorção de compostos às camadas da argila, as quais são compostas por $\mathrm{Al}_{2} \mathrm{Si}_{4} \mathrm{O}_{10}(\mathrm{OH})_{2}$. No meio ambiente observa-se a substituição na montemorilonite de alguns dos átomos de alumínio por iões magnésio e/ou ferro, e o próprio alumínio substitui alguns dos átomos de silício. O mecanismo de catálise da polimerização de nucleótidos por argilas montemorilonite não é totalmente conhecido, mas o desempenho do silício pode não ser relevante. ${ }^{72,74-77}$

\section{COMENTÁRIOS FINAIS}

O conhecimento acerca do modo como a vida na Terra teria surgido ainda se encontra por esclarecer. É muito improvável que uma via sintética tenha tido um percurso simples até ao aparecimento das primeiras biomoléculas e dos primeiros seres vivos. O contributo dos semimetais, para a origem e evolução da vida na Terra, pode ter ocorrido em vários aspetos específicos.

Os semimetais formam compostos com oxigénio que são anfóteros, isto é, podem atuar como ácidos ou bases, e esse duplo comportamento pode ter sido necessário em algumas reações, assim como a de estabilizadores das conformações mais adequadas a essas moléculas pré-biológicas. Ao nível das suas características químicas, os aniões derivados do boro e do silício podem ter interagido, sobretudo com os catiões, e desta forma terem facilitado a sua disponibilidade, o que pode ter permitido um aumento de estabilidade dos componentes de unidades essenciais para a origem e evolução da vida na Terra. Se, por um lado, os elementos metálicos foram necessários na manutenção da electroneutralidade dos ribonucleótidos (mais provável para os iões alcalinos e o ião magnésio), podem ter sido igualmente importantes como estabilizadores e ativadores de sistemas pré-bióticos.

A afinidade de alguns catiões pelos grupos hidroxilo e grupos fosfato presentes no RNA (entre outras biomoléculas), bem como a sua disponibilidade nos oceanos primitivos há $4,5 \times 10^{9}$ anos, são dois fatores muito relevantes que podem ter contribuído para que os elementos químicos, sódio, potássio, magnésio, cálcio, manganês, ferro, cobalto, níquel, e eventualmente vanádio e tungsténio, entre os metais, e boro e silício, entre os semimetais, possam ter tido importantes funções nos processos associados com a origem e a evolução da vida na Terra, uma das fronteiras atuais da Biologia., ${ }^{4,8,34}$ 


\section{NOTA FINAL}

Recentemente foi colocada a hipótese de estruturas contendo sílica poderiam ter sido protocélulas devido a terem propriedades hidrófobas e hidrófilas. ${ }^{78}$ É uma outra possibilidade de participação do silício na química pré-biótica que precisa de ser testada.

\section{AGRADECIMENTOS}

M. Aureliano agradece ao Centro de Ciências do Mar (CCMar) pelo financiamento plurianual; J. J. R. F. da Silva e J. A. L. da Silva agradecem o apoio financeiro dado pelo projeto plurianual PEst-OE/ QUI/UI0100/2011 da Fundação para a Ciência e a Tecnologia (FCT), Portugal, que permitiu a realização deste trabalho.

\section{REFERÊNCIAS E NOTAS}

1. http://pt.wikipedia.org/wiki/Semimetal, acessada em Novembro 2011.

2. Só até ao princípio de novembro de 2011 são referidas na base de dados isiknowledge 190 publicações acerca deste tópico.

3. Shriver, D. F.; Atkins, P. W.; Inorganic Chemistry, $3^{\text {rd }}$ ed., Oxford University Press: Oxford, 1999.

4. Fraústo da Silva, J. J. R.; da Silva, J. A. L.; Os Elementos Químicos e a Vida, IST Press: Lisboa, 2011.

5. Bienert, G. P.; Schussler, M. D.; Jahn, T. P.; Trends Biochem. Sci., 2008 33,20 .

6. Bhattacharjee, H.; Mukhopadhyay, R.; Thiyagarajan, S.; Rosen, B. P.; J. Biol. 2008, 7, 33.

7. da Silva, J. A. L.; Química 2006, 102, 33.

8. Fraústo da Silva, J. J. R.; Williams, R. P. J.; The Biological Chemistry of the Elements - the inorganic chemistry of life, $2^{\text {nd }}$ ed., Clarendon Press: Oxford, 2001.

9. Nisbet, E. G.; Sleep, N. H.; Nature 2001, 409, 1083.

10. Anbar, A. D.; Science 2008, 322, 1481.

11. Williams, R. P. J.; Fraústo da Silva, J. J. R.; The Chemistry of Evolution - The Development of our Ecosystem, Elsevier: Amsterdam, 2006.

12. Jolly, W. L.; Chemie des Éléments Non Métalliques, Dunod: Paris, 1967.

13. Emsley, J.; The Elements, $2^{\text {nd }}$ ed., Clarendon Press: Oxford, 1994.

14. Os biofilmes são comunidades biológicas com um elevado grau de organização, que permitem aumentar a eficácia de atividades como a virulência, a produção de antibióticos e a bioluminescência.

15. Goldbach, H. E.; Wimmer, M. A.; J. Plant Nutr. Soil Sci. 2007, 170, 39.

16. Wolkenstein, K.; Gross, J. H.; Falk, H.; Proc. Natl. Acad. Sci. U. S. A. 2010, 107, 19374.

17. Street-Perrott, F. A.; Barker, P. A.; Earth Surf. Process. Landf. 2008, 33, 1436.

18. Stolz, J. E.; Basu, P.; Santini, J. M.; Oremland, R. S.; Annu. Rev. Microbiol. 2006, 60, 107.

19. Zhao, F. J.; Ma, J. F.; Meharg, A. A.; McGrath, S. P.; New Phytol. 2009, $181,777$.

20. Pennisi, E.; Science 2010, 330, 1302.

21. Ba, L. A.; Doring, M.; Jamier, V.; Jacob, C.; Org. Biomol. Chem. 2010, 8,4203 .

22. Fraústo da Silva, J. J. R.; da Silva, J. A. L.; Quim. Nova 2009, 32, 554.

23. Oparin, A. I.; Proiskhozhdenie Zhizny, Izdatelstvo Moskovski Rabochii: Moscow, 1924; exemplo de edição em português: A Origem da Vida, $5^{\text {a }}$ ed., Vitória: Rio de Janeiro, 1963.

24. Haldane, J. B. S.; Rationalist Annu. 1929, 148, 3.

25. Miller, S. L.; Science 1953, 117, 528.

26. Rauchfuss, H.; Chemical Evolution and the Origin of Life, $1^{\text {st }}$ ed., Springer-Verlag: Berlin, 2008 .

27. Orgel, L. E.; Crit. Rev. Biochem. Mol. Biol. 2004, 39, 99.
28. Joyce, G. F.; Nature 1989, 338, 217.

29. Joyce, G. F.; Nature 2002, 418, 214.

30. Gilbert, W.; Nature 1986, 319, 618.

31. Jeffares, D. C.; Poole, A. M.; Penny, D.; J. Mol. Evol. 1998, 46,18.

32. Lincoln, T. A.; Joyce, G. F.; Science 2009, 323, 1229.

33. Vitreschak, A.G.; Rodionov, D. A.; Mironov, A. A.; Gelfand, M. S.; Trends Genet. 2004, 20, 44.

34. Amaral, A. F.; da Silva, J. A. L. Em Vida: Origem e Evolução, Levy, A.; Carrapiço, F.; Abreu, H.; Pina, M., eds.; Esfera do Caos: Lisboa, 2011, cap. 4.

35. Fry, I.; Orig. Life Evol. Biosph. 2011, 41, 3.

36. Holm, N. G.; Dumont, M.; Ivarsson, M.; Konn, C.; Geochem. Trans. 2006, 7,7

37. Anastasi, C.; Buchet, F. F.; Crowe, M. A.; Parkes, A. L.; Powner, M. W.; Smith, J. M.; Sutherland, J. D.; Chem. Biodiversity 2007, 4, 721.

38. Sutherland, J. D.; Cold Spring Harb. Perspect. Biol. 2010, 2, artigo número: a005439.

39. Powner, M. W.; Gerland, B.; Sutherland, J. D.; Nature 2009, 459, 239.

40. Baccolini, G.; Boga, C.; Micheletti, G.; Chem. Commun. 2011, 47, 3640.

41. Zimmer, C.; Science 2009, 323, 198.

42. Zubay, G.; Orig. Life Evol. Biosph. 1998, 28, 13.

43. Larralde, R.; Robertson, M. P.; Miller, S. L.; Proc. Natl. Acad. Sci. U. S. A. 1995, 92, 8158 .

44. Geraldes, C. F. G. C.; Aureliano, M.; Castro, M. M. C. A.; Saraiva, M. E.; Dias, M. B. A.; J. Coord. Chem. 1988, 17, 205.

45. Geraldes, C. F.; Castro, M. M.; J. Inorg. Biochem. 1989, 35, 79.

46. Geraldes, C. F.; Saraiva, M. E.; Dias, B. A.; J. Inorg. Biochem. 1992, 46, 99.

47. Kim, H. J.; Ricardo, A.; Illangkoon, H. I.; Kim, M. J.; Carrigan, M. A.; Frye, F.; Benner, S. A.; J. Am. Chem. Soc. 2011, 133, 9457.

48. Ricardo, A.; Carrigan, M. A.; Olcott, A. N.; Benner, S. A.; Science 2004, 303, 196.

49. Šponer, J. E.; Sumpter, B. G.; Leszczynski, J.; Šponer, J.; FuentesCabrera, M.; Chem.--Eur. J. 2008, 14, 9990.

50. Amaral, A. F.; Marques, M. M.; da Silva, J. A. L.; Fraústo da Silva, J. J. R.; New J. Chem. 2008, 32, 2043.

51. Ortiz, P.; Fernández-Bertrán, J.; Reguera, E.; Spectrochim. Acta, Part A 2005, 61, 1977.

52. Lambert, J. B.; Gurusamy-Thangavelu, S .A.; Ma, K.; Science 2010, 327, 984.

53. Vazquez-Mayagoitia, A.; Horton, S. R.; Sumpter, B. G.; Šponer, J.; Šponer, J. E.; Fuentes-Cabrera, M.; Astrobiology 2011, 11, 115.

54. Lambert, J. B.; Lu, G.; Singer, S. R.; Kolb V. M.; J. Am. Chem. Soc. 2004, 126, 9611.

55. Kim, H. J.; Benner, S. A.; Science 2010, 329, 902.

56. Saladino, R.; Neri, V.; Crestini, C.; Costanzo, G.; Graciotti, M.; Di Mauro, E.; J. Am. Chem. Soc. 2008, 130, 15512.

57. Os minerais de Fe permitem reforçar a hipótese do «Mundo ferro-enxofre» (a qual não é incompatível com a do «RNA world»), pois de acordo com esta hipótese a síntese das primeiras moléculas orgânicas teria ocorrido na superfície de minerais $\mathrm{Fe}-\mathrm{S}$, em fontes hidrotermais, através de fixação de dióxido de carbono. ${ }^{8}$

58. Saladino, R.; Barontini, M.; Cossetti, C.; Di Mauro, E.; Crestini, C.; Orig. Life Evol. Biosph. 2011, 41, 317.

59. Saladino, R.; Neri, V.; Crestini, C.; Costanzo, G.; Graciotti, M.; Di Mauro, E.; J. Mol. Evol. 2010, 71, 100.

60. Cleaves, H. J.; Nelson, K. E.; Miller, S. L.; Naturwissenschaften 2006 , 93, 228.

61. Miyakawa, S.; Cleaves, H. J.; Miller, S. L.; Orig. Life Evol. Biosph. 2002, 32, 195.

62. Miyakawa, S.; Cleaves, H. J.; Miller, S. L.; Orig. Life Evol. Biosph. 2002, 32, 209 .

63. Zubay, G.; Mui, T.; Orig. Life Evol. Biosph. 2001, 31, 87. 
64. Nelson, K. E.; Robertson, M. P.; Levy, M.; Miller, S. L.; Orig. Life Evol. Biosph. 2001, 31, 221.

65. Oró, J.; Nature 1961, 191, 1193.

66. Bernal, J. D.; Nature 1960, 186, 694.

67. Mer é uma unidade de dimensão das moléculas poliméricas, que corresponde à maior unidade básica que se pode encontrar num polímero, no caso do RNA, um ribonucleótido.

68. Monnard, P. A.; Kanavarioti, A.; Deamer, D. W.; J. Am. Chem. Soc. 2003, 125, 13734

69. Shapiro, R.; IUBMB Life 2000, 49, 173.

70. Sawai, H.; J. Am. Chem. Soc. 1976, 98, 7037.

71. Sawai, H.; Higa, K.; Kuroda, K.; J. Chem. Soc., Perkin Trans. 1992, 1, 505 .
72. Ferris, J. P.; Elements 2005, 1, 145.

73. As argilas montemorilonite, muito comuns na crusta terrestre, formam-se quando cinzas vulcânicas são sujeitas a um processo natural de decomposição pela ação de fatores ambientais.

74. Ertem, G.; Ferris, J. P.; J. Am. Chem. Soc. 1997, 119, 7197.

75. Ferris, J. P.; Philos. Trans. R. Soc. B - Biol. Sci. 2006, 361, 1777.

76. Kawamura, K.; Ferris, J. P.; J. Am. Chem. Soc. 1994, 116, 7564.

77. Franchi, M.; Ferris, J. P.; Gallori, E.; Orig. Life Evol. Biosph. 2003, 33,

78. Li, M.; Green, D. C.; Anderson, J. L. R.; Binks, B. P.; Mann, S.; Chem. Sci. 2011, 2, 1739 